\title{
JACARANDA RONDONIAE VATTIMO N.SP. BIGNONIACEAE - SEÇÃO DILOBOS ENDL.
}

ITALO DE VATTIMO

Pesquisador do

Jardim Botânico - RJ

Continuando o estudo de material botânico herborizado, do INPA, das espécies de Jacaranda Jussieu (Bignoniaceae - Seção Dilobos Endl.), da região Norte do Brasil, o autor teve a oportunidade de encontrar uma nova espécie desse gênero, a qual denominou de Jacaranda rondoniae Vattimo n. sp., sendo o epiteto dedicado ao Território de Rondônia onde foi encontrada.

\section{Jacaranda rondoniae Vattimo $\mathrm{n}$. sp.}

Holotypus: C. D. Mota et L. Coêlho nọ 196, Território de Rondônia (INPA).

Lianae ("cipo" ex C. D. Mota et L. Coêlho), trunco ligneo, foliis compositis, oppositis, decussatis, paribipinnatis, breviuscule petiolatis rachidibus subteretibus ad apicem subapplanatis, supra late canaliculatis, striatis, brunneo-purpureo-rufescentibus, puberulis, lenticellatis et valde pedicellato-capitato-pilosis. Pinnae oppositae imparipinnatae, 4-jugatae foliolis oppositis, rachilis subteretibus ad apicem subapplanatis, super alis erectis et angustis, striolatis, brunneo-purpureo-rufescentibus puberulis, valde pedicellato-capitato-pilosae. Foliola zigomorpha, subovata vel subelliptica, membranacea apice acuminata, acuta vel obtusa, et basi acuta, breve petiolulata, margine integra plana, circa $8,5 \mathrm{~cm}$ longa, $4 \mathrm{~cm}$ latitudine maxima, super atro-brunnea subtus pallidiora viridia, utrinque opaca, esquamis paucis, pedicellato-capitato-multipilosa, puberula, juvenilia subtus velutina excepta.

Nervi brochidrodomi (Ettingshausen, 1861) brunneo pallidi vel atro-rufescentes, striati. Inflorescentia paniculata axillaris, bracteolis supra multipuberulis et pedicellatocapitato-pilosis, subtus glabris, cuculatis crassis vel delicatis planis, circa 1,5 mm longis pedicellorum basi et $2 \mathrm{~mm}$ rachidis basi. Rachis brevis subteres, brunneo-purpureorufescens, puberula et pedicellato-capitato-pilosa, squamis raris; rachidis pedunculis et pedicellis circa $2 \mathrm{~mm}$ longis, medio vel basi calicis insertis, interdum lateralibus, planis, 
striatis, pubescentibus, pedicellato-capitato-pilosis, brunneo-purpureo-rufescentibus. Calyx gamosepalus zigomorphus vel assymetricus inaequilongus, campanulatus, subplanus, coriaceus, atro-brunneus, extus paucipuberulus, glandulosus, rugosus, intus glaber, margine subtruncatus leve pentaundulatus, circa $8 \mathrm{~mm}$ longus, interdum squamosus. Corolla gamopetala, assymetrica, membranacea, anguste (6-1) campanulata, subapplanata, circa $6,5 \mathrm{~cm}$ longa, quinqueloba, extus puberula et valde pedicellatocapitato-pilosa, intus paucivillosa. Stamina didynama applanata, striata ad $13 \mathrm{~mm}$ ultra basin affixa, minora $19 \mathrm{~mm}$ longa et majora $24 \mathrm{~mm}$ longa. Antherae dilobae circa $2 \mathrm{~mm}$ longae et $0,8 \mathrm{~mm}$ latae. Staminodium apice bilobulatum circa $3,5 \mathrm{~cm}$ longum et $1 \mathrm{~mm}$ latum, apice ad $2,9 \mathrm{~cm}$ villosum et ad 2,9-3,5 cm glabrum, striatum. Gynaeceum gamo. carpelare, ovario supero, biloculare, glabro, striato, brunneo-atro-purpureo, applanato, circa $1,5 \mathrm{~mm}$ alto, $1,8 \mathrm{~mm}$ longo, $0,8 \mathrm{~mm}$ latitudine maxima, multiovulato. Stylus applanatus, dimidio inferiore sulcatus, brunneo-flavus, glabrus, striatus, circa $31 \mathrm{~mm}$ longus et $0,5 \mathrm{~mm}$ latitudine maxima, stigmate bilamellato, laciniis subovatis subinaequalibus. Discus striatus, glabrus, circa $1 \mathrm{~mm}$ altus, $2 \mathrm{~mm}$ longus et $1 \mathrm{~mm}$ latus. Fructus capsularis loculicidus, grandis, subapplanatus, subellipticus vel subovatus, apice acutus, basi obtusus, verruculosus, glabrus, lignosus margine integer, claro-brunneus, $10,5 \mathrm{~cm}$ longus, $6,8 \mathrm{~cm}$ latus. Semina alis hyalinis subovatis.

Ad Jacaranda rufa Manso affinis, sed differt rachide pinnarum.

HABITAT: TERRITÓRIO DE RONDÔNIA: Porto Velho, sub-base do aeroporto, leg. C. D. Mota e L. Coêlho nọ 196, 22-9-1975, Lianae ("cipó"), flores rosei, fructus brunneus, "capoeira" brevis in terra argillosa.

O autor dá a seguir um estudo mais profundo da morfologia externa da espécie, acompanhado de dados anatômicos:

Liana ("cipó" ex C. D. Mota et L. Coêlho) de caule lenhoso. Folhas compostas, opostas, decussadas, paribipinadas, com pecíolos curtos, que se prolongam em raques subcilíndricas, para o ápice subachatadas, superiormente largamente canaliculadas, estrioladas, castanho-purpurino-rusfecentes, pubérulas, com muitos pêlos pedicelados capitados e com lenticelas. Pinas opostas imparipenadas, com cerca de 4 jugos de folíolos opostos, ráquilas subcilíndricas, subachatadas para o ápice, superiormente com alas eretas e estreitas, estrioladas, castanho-purpurino-rufescentes, pubérulas e com muitos pêlos capitado-pilosos. Folíolos zigomorfos, em geral subovados ou subelíticos, membranáceos, com o ápice acuminado, agudo ou obtuso e base aguda terminando até cerca de $2 \mathrm{~mm}$ do ponto de contato do peciólulo com a ráquila, de margens íntegras planas, com até cerca de $8,5 \mathrm{~cm}$ de comprimento e $4 \mathrm{~cm}$ de maior largura, com a epiderme superior castanha escura e a inferior verde clara, ambas sem brilho, com algumas escamas, com muitos pêlos pedicelados capitados, pubérulas, exceto os folfolos jovens, que são velutinos na epiderme inferior.

O padrão de nervação é do tipo broquidródomo (Ettingshausen, 1861), as nervuras castanhas claras a rufescentes escuras estrioladas. $\mathrm{Na}$ epiderme superior as nervuras ficam depressas ou ao nível das células epidérmicas e na epiderme inferior as nervuras primárias e secundárias de primeira ordem são prominentes, as secundárias de segunda 
ordem e terciárias ficam promínulas, as demais ficam ao nível das células epidérmicas. Há de 8-11 nervuras secundárias de primeira ordem, de cada lado da nervura primária.

Inflorescências laterais axilares em panículas de ramos curtos, com bractéolas castanhas escuras, na face superior muito pubérulas e com pêlos pedicelados capitados e na inferior glabras, espessas cuculadas ou delgadas subchatas, com cerca de $1,5 \mathrm{~mm}$ de comprimento na base dos pedicelos e pedúnculos e $2 \mathrm{~mm}$ na base das raques. Raques curtas subcilíndricas, pubérulas e com pêlos pedicelados capitados, com raras escamas; pedicelos com cerca de $2 \mathrm{~mm}$ de comprimento, inseridos na parte central da base do cálice, às vezes lateralmente e ráquilas e pedúnculos subchatos, estriolados, muito pubérulos e com pêlos pedicelados capitados castanho-purpuríneo-rufescentes. Cálice gamossépalo zigomorfo ou assimétrico inequilongo, campanulado, subachatado, coriáceo, castanho escuro, externamente paucipubérulo, glanduloso, rugoso e internamente glabro, de bordo subtruncado levemente pentaondulado, com cērca de $8 \mathrm{~mm}$ de comprimento e com algumas escamas. Corola gamopetala, assimétrica, membranácea, estreitamente (6-1) campanulada, achatada, com ceerca de até $6,5 \mathrm{~cm}$ de comprimento, pentalobada, externamente pubérula, com muitos pêlos pedicelados capitados e internamente vilosa com pêlos longos e flexuosos, diáfanos e capitados no ápice, em geral na área dos lobos e da inserção dos estames. Estames didínamos com filetes achatados, estriolados, fixados a $13 \mathrm{~mm}$ acima da base da corola, os menores com $19 \mathrm{~mm}$ e os maiores com 24 $\mathrm{mm}$ de comprimento, ambos com $1 \mathrm{~mm}$ de maior largura, com poucos e raros pêlos muito curtos de ápice capitado. Anteras dilobas, vistas ventral e dorsalmente côncavoplanas, com cerca de $2 \mathrm{~mm}$ de comprimento e $0,8 \mathrm{~mm}$ de maior largura. Estaminódio achatado com ápice bilobulado, com cerca de $3,5 \mathrm{~cm}$ de comprimento e $1 \mathrm{~mm}$ de maior largura, do ápice até $2,9 \mathrm{~cm}$ é viloso, de $2,9-3,5 \mathrm{~cm}$ é glabro, fixado a $13 \mathrm{~mm}$ acima da base da corola. Gineceu gamocarpelar, ovário súpero, bicarpelar, bilocular, multiovulado, castanho-purpuríneo atro, estriolado, glabro, achatado, com até 1,5 mm de altura, $1,8 \mathrm{~mm}$ de comprimento e $0,8 \mathrm{~mm}$ de maior largura. Estilete achatado, sulcado inferiormente, castanho-amarelado, glabro, estriolado, com cerca de $31 \mathrm{~mm}$ de comprimento e $0,5 \mathrm{~mm}$ de maior largura, prolongando-se em estigma glabro bilamelado: com lacínias subovais, ligeiramente desiguais, uma com cêrca de $1,3 \mathrm{~mm}$ de comprimento e $1 \mathrm{~mm}$ de largura e outra com 1,5 mm de comprimento e 1,2 $\mathrm{mm}$ de largura, de ápice obtuso e bordo paucicrenulado. Disco estriolado, mais desenvolvido que a base do ovário, glabro, com cerca de até $1 \mathrm{~mm}$ de altura, $2 \mathrm{~mm}$ de comprimento e $1 \mathrm{~mm}$ de maior largura.

Os frutos são cápsulas de deiscência loculícida, grandes, subachatadas, subelíticas ou subovais, de ápice agudo e base subarredondadas, com pequeno prolongamento que a liga ao pedúnculo, miudamente verruculosa, glabra, lenhosa de margem inteira, castanha clara, com cerca de $10,5 \mathrm{~cm}$ de comprimento (corpo da cápsula 10,2 cm, prolongamento $3 \mathrm{~mm}$ ) maior largura $6,8 \mathrm{~cm}$. Sementes aladas subobovadas.

Dados fenológicos: florece e frutifica em setembro - C. D. Mota e L. Coêlho (INPA).

Observações ecológicas: ocorre em capoeira baixa, em solo argiloso - C. D. Mota e L. Coêlho.

Distribuição geográfica: BRASIL: Território de Rondônia. 


\section{AGRADECIMENTOS}

Ao Conselho Nacional de Desenvolvimento Científico e Tecnológico, pela bolsa concedida ao autor, que permitiu realizar o presente trabalho.

Ao Diretor do Instituto Nacional de Pesquisa da Amazônia (INPA), Centro de Pesquisas Florestais, Manaus-Amazonas.

Ao técnico do laboratroio fotográfico do Jardim Botânico do Rio de Janeiro, Sr. Mario da Silva.

\section{ABSTRACT}

The Author describes the new species Jacaranda rondoniae Vattimo n. sp. (Bignoniaceae, Sectio Dilobos Endl.). The species is related to J. rufa Manso, differing immediately by the pinnae rachis.

\section{BIBLIOGRAFIA}

BUREAU, E., et K. SCHUMANN, 1897. Bignoniaceae, in Martius, FI. Bras. 8(2): 386-387.

CORREA, M. P., 1931. Dicionário das Plantas úteís do Brasil e das exóticas cultivadas, vol. II, 64.

VATTIMO, ITALO DE, 1977. Espécies do género Jacaranda Jussieu (Bignoniaceae), que ocorrem no Estado do Rio de Janeiro - Seção monolobos P. DC.), in Rodr, no 42, 143-157.

VATTIMO, IITALO DE, 1977. Jacaranda paraensis (Huber) Vattimo stat. nov. Bignoniaceae Seçäo Monolobos P. DC.), in Rodr. no 43, 285-297.

VATTIMO, ITALO DE, 1978. Uma nova espécie de Jacaranda Jussieu (Bignoniaceao - Seção Monolobos P.DC.), in Rodr. no 44, 231-243. 


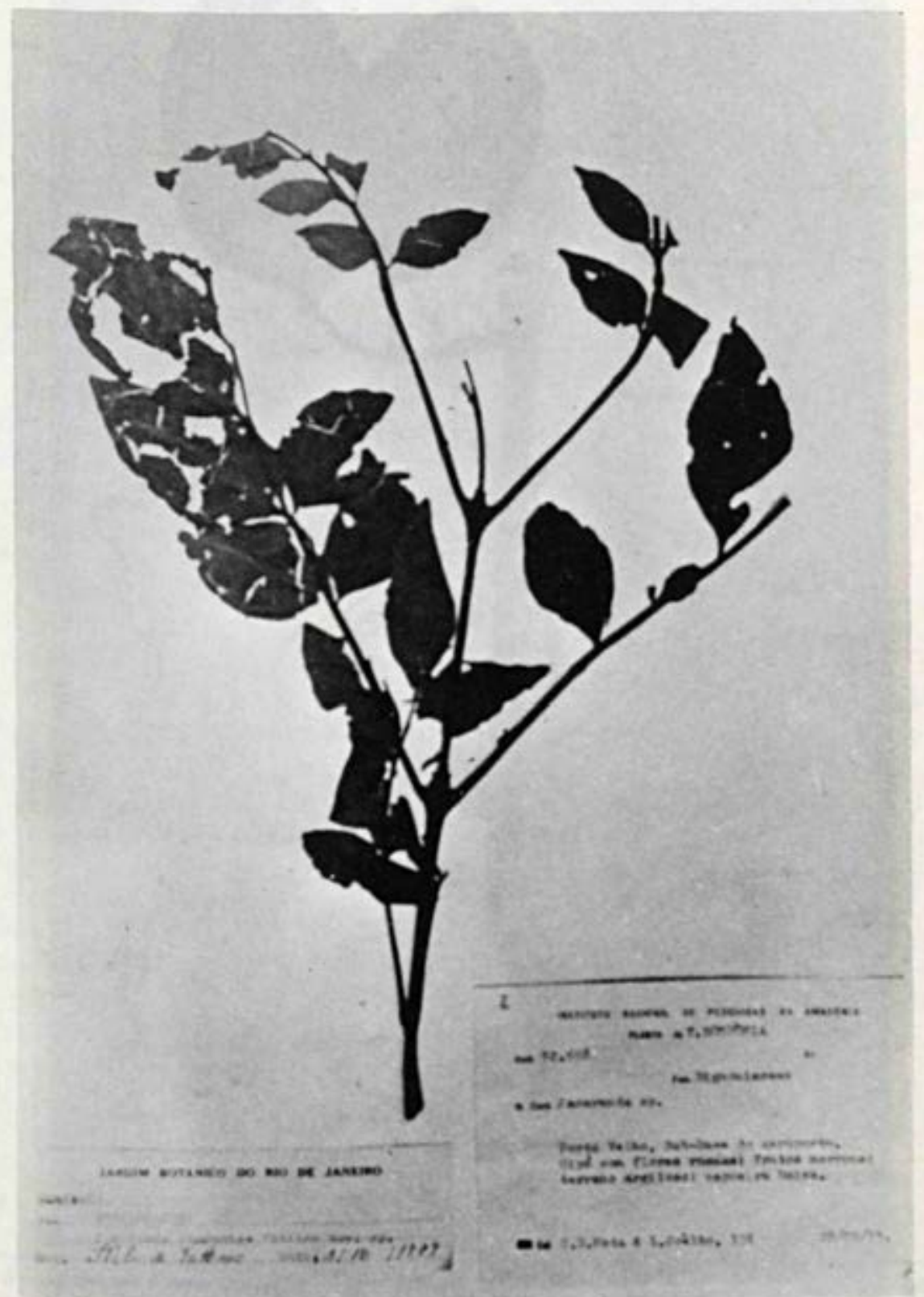

Est. 1 - Jacaranda rondoniae Vattimo nov. sp. 


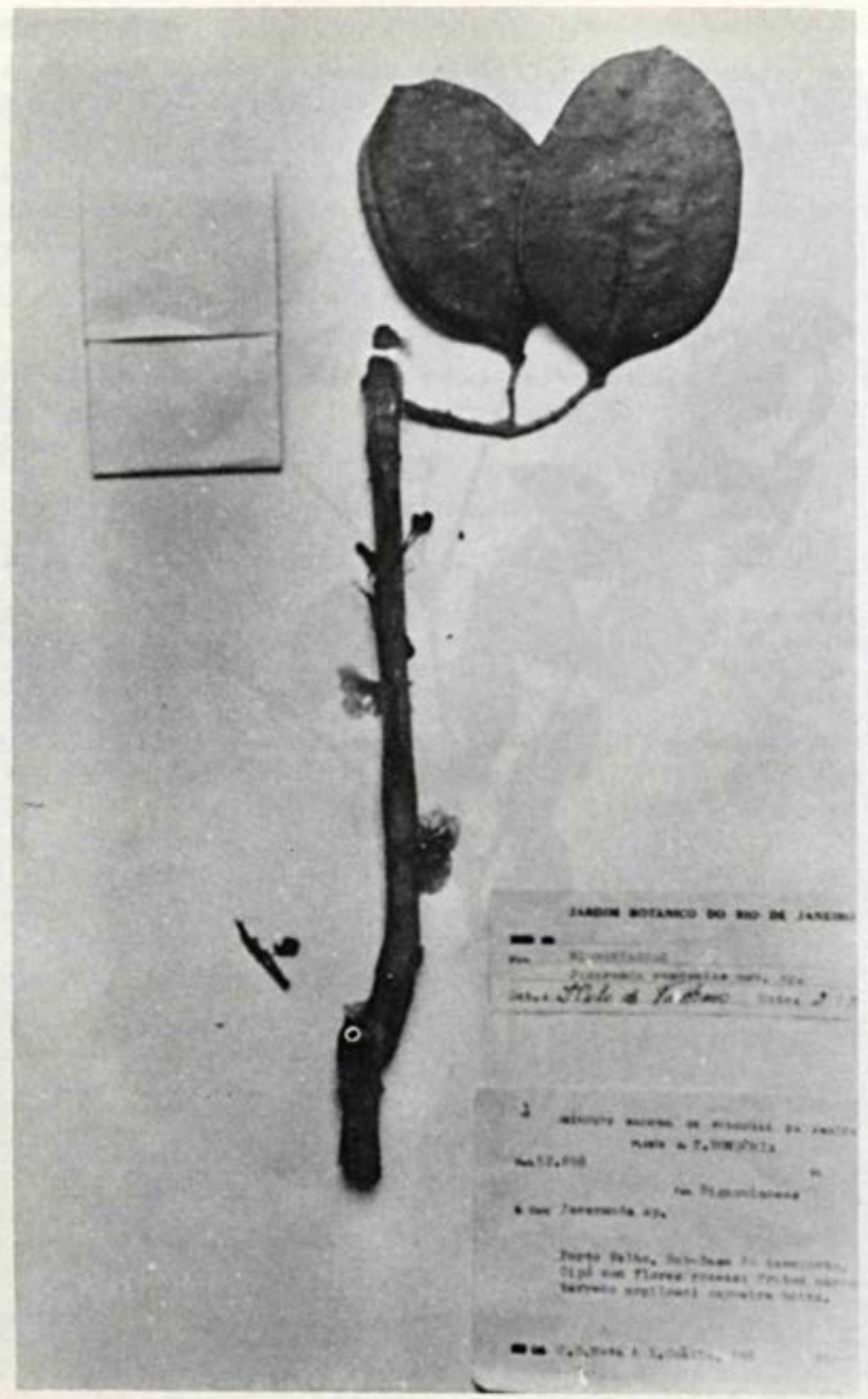

Est. 2 - Jacaranda rondoniae Vattimo nov. sp.: frutos 

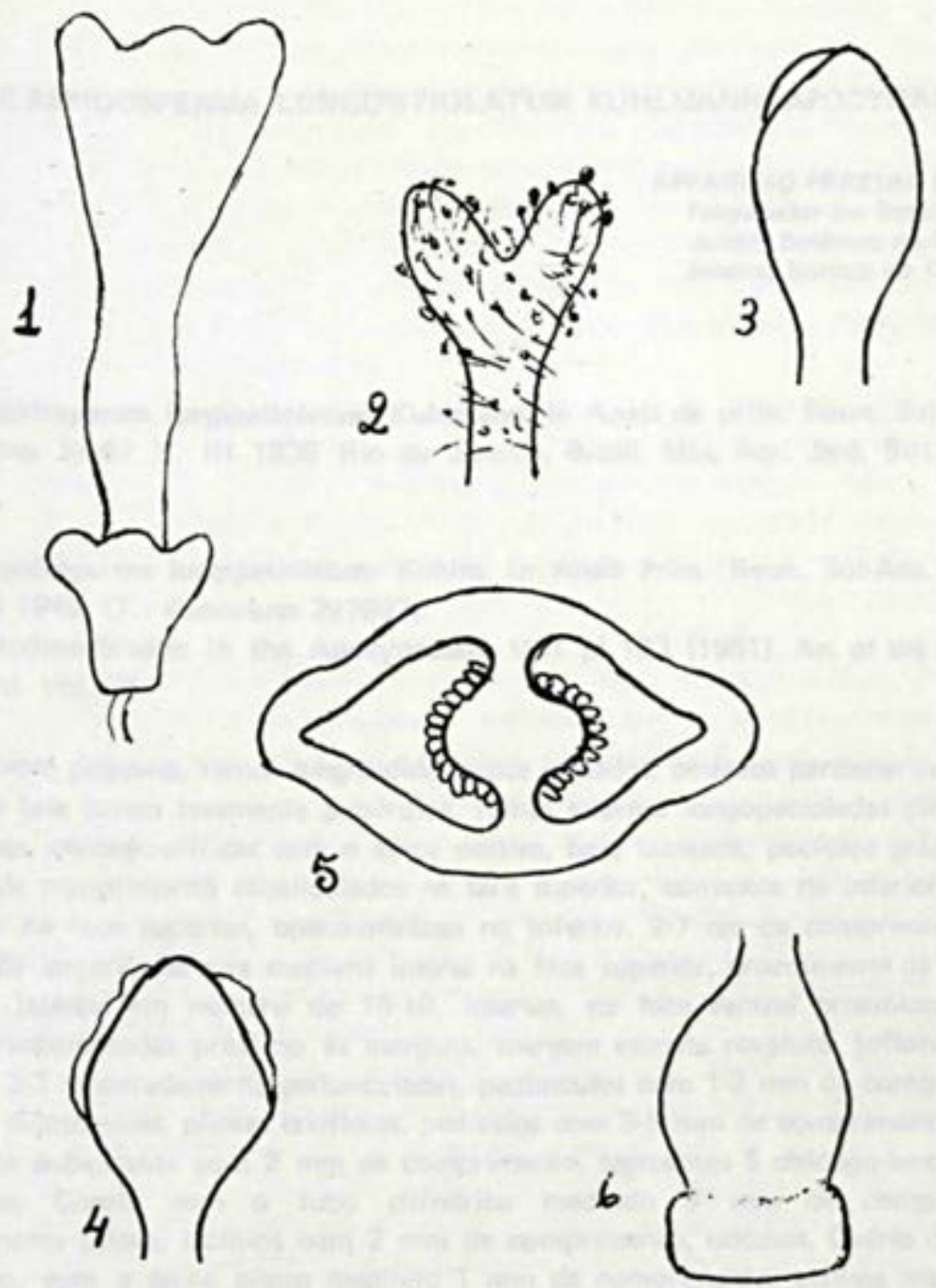

Est. 3 - Jacarande rondoniae Vattimo nov. sp.: fig. 1: flor; fig. 2: ápice bilobulado do estamin\&dio; figs. 3 e 4: estígma, lacínias ligeiramente desiguais com o ápice obtuso e bordo paucicrenulado; fig. 5: seçảo transversal do ovário: fig. 6: parte do gineceu com ovário e disco. 